A. Malaviya Consultant for: Advisory board of IPCA, Janssen, Pfizer, Roche, BMS,Dr. Reddy's, Zydus

DOI: 10.1136/annrheumdis-2017-eular.2344

\section{AB1227-HPR VALIDATION AND APPLICABILITY OF A NOVEL OSTEOMALACIA KNOWLEDGE BASED EDUCATIONAL INSTRUMENT (OKQ)}

S. Robinson ${ }^{1}$, R. Waxman ${ }^{2}$, D. Walker ${ }^{1}$, P. Helliwell ${ }^{2}$, A. Adebajo ${ }^{3}$. ${ }^{1}$ Rheumatology, North Tynside General Hospital, North Shields; ${ }^{2}$ Leeds Institute of Rheumatic and Musculoskeletal Medicine, University of Leeds, Leeds; ${ }^{3}$ Faculty of Medicine, Dentistry and Health, University of Sheffield, Sheffield, United Kingdom

Background: Osteomalacia is caused by a deficiency of vitamin D and can be corrected by changes in diet, lifestyle and supplementation. Consequently, it is a condition where education has a primary role in prevention.

Objectives: If educational interventions are to be developed and evaluated, then an instrument for measuring knowledge is required. This has led us to develop a novel Osteomalacia Knowledge Questionnaire (OKQ).

Methods: Based on nominal group technique, a steering group of people who are knowledgeable about osteomalacia, educational theory and questionnaire development was convened. The group decided to use true and false questions. Important areas of knowledge of osteomalacia were first determined by the group and then relevant statements which were true or false were written and grouped into 8 sections of 5 questions, each covering the different areas of knowledge. This resulted in a knowledge instrument with 40 questions in all. The questions were tested for utility and ambiguity in the group and modified and replaced accordingly.

The questionnaire was then trialled in 37 people of South Asian origin (an osteomalacia susceptible population), in three groups. Participants were initially administered the OKQ and then received an educational intervention comprising a practitioner led education session on osteomalacia, including a presentation and written or electronic material. Participants were re tested with the OKQ after 6 weeks.

Although there is no "gold standard" for measuring knowledge about osteomalacia, if effective, increased knowledge should lead to an increase in vitamin $D$ (Vit D) levels and a decrease in parathormone (Pth) levels. Vitamin D and Parathormone levels were measured alongside the OKQ in 2 of the groups before and after the educational intervention

Results: Baseline knowledge about osteomalacia was low pre education averaging only 12.7 out of 40 (range $0-29)(n=37)$.

A total of 30 participants $(81 \%)$ attended for the follow up test. They averaged a score of 13.9 at baseline and 23.4 at follow up. This was statistically significant $(p=0.002$ Mann Whitney) and demonstrated sensitivity to change of the OKQ. Knowledge at baseline was correlated with vit $D$ and Pth blood levels for two of the groups $(n=27)$. This showed correlation coeficients of 0.128 and -0.407 respectively. For change of knowledge and change of parathormone $(n=21)$ the $r$ value was -0.324 suggesting a relationship between knowledge and Pth that is worthy of confirmation through further studies.

Conclusions: A novel questionnaire has been developed that has face validity for testing knowledge about osteomalacia. It has proved feasible and shown sensitivity to change. It has also shown promising correlation with biochemical measures of osteomalacia.

Acknowledgements: This study was funded by Arthritis Research United Kingdom.

Disclosure of Interest: None declared

DOI: 10.1136/annrheumdis-2017-eular.5280

\section{AB1228-HPR IN ABSENCE OF SPECIFIC ADVICE, WHAT DO THEY EAT AND AVOID? DOES IT MATTER? DIET EVALUATION OF INDIAN (ASIAN) PATIENTS OF RA IN A COMMUNITY RHEUMATOLOGY CLINIC}

T. Kianifard, M. Saluja, A. Chopra. Rheumatology, Center for Rheumatic Diseases, Pune, India

Background: Diet in RA is generally considered to be inadequate/inappropriate. Rheumatologists often neglect this important patient concern. ACR/EULAR guidelines do not provide adequate advice. Ayurveda (ancient India medicine system) with highly restricted diet is popular with Indian patients.

Objectives: To evaluate diet adequacy in patients of RA in our setting

Methods: 139 consenting patients (ACR 1987 classified)on long term supervised care and 165 unmatched healthy subjects (mean age 37.7 years) were interviewed in no particular order as per protocol; cross sectional design. A 10 day diet recall period and a-priori validated questionnaires was used. National (India) recommended daily allowance (RDA) and diet analysis (web based and food composition tables) methods were used.Standard CRF captured clinical data [mean pain VAS $4.6 \mathrm{cms}$, mean HAQ score (Indian version) 6.5]. Standard statistical analysis (SPSS) was done; significant $p<0.05$.

Results: Table 1 (women) and 2 (men) show average daily energy expenditure and consumption of selected food items, RDA and $p$ values (on comparison: $P$ (1) for patient versus control, $P$ (2) for patient versus RDA: $p$ by Mann
Whitney). Compared to RDA, patient consumption was significantly higher for most of the items except K; includes calcium, phosphorus, zinc, iron, folic acid, vitamin B group (data not shown in Tables). When compared to healthy subjects, consumption was significantly lower for female patients but not different for men (except for K). Reduction in diet $\mathrm{K}$ in RA group was more pronounced for women. All patients tested normokalemic (mean serum K+ $4.37 \mathrm{mEg} / \mathrm{l}$ ). No meaningful correlation between diet components and disease measures (data not shown).Food avoidance patterns identified a-priori did not seem to impact disease measures (data not shown). 44\% RA and 77\% controls consumed vegetarian diet (excluding eggs). Patient dependence for diet recall and measure was the important limiation.

Table 1. Women RA subjects and healthy control

\begin{tabular}{lccccc}
\hline Component & Patient $(\mathrm{n}=115)$ & Control $(\mathrm{n}=122)$ & $\mathrm{RDA}$ & $\mathrm{P}(1)$ & $\mathrm{P}(2)$ \\
\hline Energy (kilocalorie) & 2825 & 3436 & 2230 & 0.02 & 0.03 \\
Carbohydrate $(\mathrm{g} / \mathrm{d})$ & 457 & 532 & NA & 0.16 & 0.00 \\
Protein $(\mathrm{g} / \mathrm{d})$ & 94 & 127 & 55 & 0.00 & 0.00 \\
Fat $(\mathrm{g} / \mathrm{d})$ & 69 & 84 & 25 & 0.00 & 0.00 \\
Sodium $(\mathrm{mg} / \mathrm{d})$ & 3112 & 3221 & 1902 & 0.56 & 0.00 \\
Potassium $(\mathrm{mg} / \mathrm{d})$ & 1223 & 3393 & 3225 & 0.000 & 0.00 \\
\hline
\end{tabular}

Table 2. Men RA subjects and healthy controls

\begin{tabular}{lccccc}
\hline Component & Patient $(\mathrm{n}=22)$ & Control $(\mathrm{n}=43)$ & RDA & P1 & P2 \\
\hline Energy $($ Kcal) & 2737 & 2829 & 2730 & 0.74 & 0.87 \\
Carbohydrate $(\mathrm{g} / \mathrm{d})$ & 439 & 425 & NA & 0.08 & - \\
Protein $(\mathrm{g} / \mathrm{d})$ & 92 & 109 & 60 & 0.33 & 0.07 \\
Fat $(\mathrm{g} / \mathrm{d})$ & 68 & 77 & 30 & 0.36 & 0.01 \\
Sodium $(\mathrm{mg} / \mathrm{d})$ & 3156 & 3180 & 2012 & 0.5 & 0.03 \\
Potassium $(\mathrm{mg} / \mathrm{d})$ & 1755 & 3562 & 3750 & 0.002 & 0.00 \\
\hline
\end{tabular}

Conclusions: The diet of RA patients seemed adequate except for an intriguingly low K. We speculate that patients eat lesser vegetables and fruits that source $\mathrm{K}$. $\mathrm{K}$ sub serves several physiological functions that may be deranged in RA and contribute to disease progression. This would need further investigation.

Acknowledgements: In contrary to our expectations and reassuringly, the diet of RA patients seemed adequate except for an intriguingly low potassium which should be investigated. We speculate that patients eat lesser vegetables and fruits that source potassium.

Disclosure of Interest: None declared

DOI: 10.1136/annrheumdis-2017-eular.4335

\section{AB1229-HPR EVALUATION OF RHEUMATOLOGY NURSE-LED CLINIC IN MANAGING PATIENTS WITH RHEUMATOID ARTHRITIS: A RETROSPECTIVE STUDY}

Y.M.E. Leung ${ }^{1}$, K.Y. Wong ${ }^{2}$, L.S. Tam ${ }^{1} .{ }^{1}$ Department of Medicine and Therapeutics, Prince of Wales Hospital; ${ }^{2}$ School of Nursing, Hong Kong Polytechnic University, Hong Kong, Hong Kong

Background: Rheumatoid arthritis (RA) is a chronic, systemic, autoimmune disease characterized by inflammation of the synovial joints. Management of RA patients are usually provided by rheumatologists only. Enhanced care provided by rheumatology nurses between rheumatologist consultations may have beneficial effects in terms of symptom control. In Hong Kong, whether rheumatology nurse care model can favor to patient outcomes remained uncertain.

Objectives: The aim of the study was to examine the clinical effectiveness of rheumatology nurse clinic in controlling disease activity as expressed in change of Disease Activity Score in 28 joints in RA patients compared with usual care led by rheumatologists only.

Methods: This was a retrospective study. Two historical groups of RA patients (30 patients at each group) were identified from attendance records between $1 / 1 / 2015$ and 20/7/2015 at the rheumatology outpatient clinics. Group 1 comprised of patients who attended rheumatology nurse clinic in between the doctor clinic consultations. Patient education delivered by the rheumatology nurse included disease mechanism, treatment aim, pain management and checking medication adherence according to prescription. RA treatment could also be intensified if needed. Group 2 comprised of patients managed by rheumatologists only. Primary outcomes were changes in disease activity at follow-up visit after the doctor clinic and nurse clinic.

Results: The mean follow-up duration for the study cohort was 20 weeks (median: 22.5 weeks). Patient global assessment and DAS 28 were similar for both groups at baseline. At follow-up, patient global assessment and in the nurse group (Group 1) decreased from mean \pm SD: $42 \pm 24.7$ at baseline to $28.7 \pm 24.6$ at follow-up, which was approaching the minimal clinically important improvement (MCll= -15). With regards to DAS28, there was a $8.2 \%$ decrease (absolute change: $-0.38 \pm 1.14)$ in DAS28 in group 1 suggesting a trend of improvement $(p=0.081)$ The corresponding decrease in group 2 was $1.2 \%$ (absolute change: $-0.05 \pm 1.47$ ) and such decrease was not significant $(\mathrm{p}=0.863)$. Changes in DAS28 did not exceed minimal clinically important improvement in both groups $(M C \|=-1.2)$.

Conclusions: This study demonstrates the short-term benefit of a nurseled program on RA disease management. Future multi-center studies with a randomized controlled design and a larger sample will be required to confirm our findings. 
Abstract AB1229-HPR - Table

\begin{tabular}{|c|c|c|c|c|c|c|}
\hline \multirow[t]{2}{*}{ Variables } & \multicolumn{3}{|c|}{ Nurse clinic $(n=30)$} & \multicolumn{3}{|c|}{ Doctor clinic $(n=30)$} \\
\hline & Baseline & Follow-up & $\overline{p \text {-value }}$ & Baseline & Follow-up & $\mathrm{p}$-value \\
\hline Tender joint count & $4(2,9)$ & $2.5(1,8.25)$ & 0.202 & $1.0(0,6.25)$ & $1.5(0,5.00)$ & 0.715 \\
\hline Swollen joint count & $1(0,3)$ & $0.5(0,3)$ & 0.624 & $1.0(0,3.25)$ & $1.0(0,4.25)$ & 0.526 \\
\hline Patient global assessment & $42.0 \pm 24.7$ & $28.7 \pm 24.6$ & 0.009 & $42.7 \pm 24.9$ & $41.3 \pm 23.7$ & 0.838 \\
\hline $\mathrm{ESR}, \mathrm{mm} /$ hour & $35.6 \pm 19.2$ & $37.0 \pm 22.0$ & 0.639 & $39.0 \pm 19.6$ & $40.7 \pm 25.3$ & 0.677 \\
\hline CRP, mg/L & $4.6(1.0,12)$ & $2.2(0.7,8.3)$ & 0.808 & $2.95(0.98,7.00)$ & $3.05(1.30,13.1)$ & 0.274 \\
\hline DAS28 score & $4.53 \pm 1.15$ & $4.16 \pm 1.31$ & 0.081 & $4.14 \pm 1.01$ & $4.09 \pm 1.23$ & 0.863 \\
\hline
\end{tabular}

Acknowledgements: The author is very grateful to the supervisors from, Professor Wong Kam Yuet, Frances, Hong Kong Polytechnic University; Professor Tam Lai Shan and Dr Zhu Yaner, Tracy the Chinese University of Hong Kong. Lastly, the author would like to thank her parents and friends for their support.

Disclosure of Interest: None declared

DOI: 10.1136/annrheumdis-2017-eular.6236

\section{AB1230-HPR A SURVEY TO ESTABLISH CURRENT PRACTICE IN ADDRESSING WORK ISSUES AMONG PEOPLE WITH INFLAMMATORY ARTHRITIS IN THE IRISH CLINICAL SETTING}

Y. Codd ${ }^{1,2}$, T. Stapleton ${ }^{1}$, R. Mullan ${ }^{2,3}$, D. Kane ${ }^{2,3} \cdot{ }^{1}$ Discipline of Occupational Therapy, Trinity College Dublin, Dublin; ${ }^{2}$ Rheumatology Department, Naas General Hospital, Naas, Co. Kildare; ${ }^{3}$ Rheumatology Department, Tallaght Hospital, Dublin, Ireland

Background: Inflammatory arthritis strongly correlates with work disability. Treatment guidelines recommend work support but data are lacking on rheumatology clinicians' perspectives on work referral and extent of work support within current rheumatology services for this population.

Objectives: To scope the need for and patterns of work referral, and examine the extent and type of work support currently available in Irish rheumatology services for people with inflammatory arthritis. To identify factors that help or hinder employment-related service provision. To explore the role of occupational therapy in addressing work with this population from the perspectives of the other members of the rheumatology team and current practices and challenges.

Methods: A questionnaire concerning work support provision was distributed via online survey to doctors, nurses and physiotherapists working in clinical rheumatology in Ireland.

Results: Response rate of $22 \%$ was achieved and total sample of 73 analysed. Respondents indicated that $71 \%$ of service users were of working age and the majority of respondents (95\%) agreed that addressing employment retention was within the remit of rheumatology services. Over half of respondent $(55 \%)$ of respondents estimated that $25-49 \%$ of their caseload had work needs. Work was usually addressed if clients raised work concerns (94\%), client reports work absenteeism $(83 \%)$, client's work involved manual component $(75 \%)$. Barriers to addressing work included limited time in clinical setting (92\%); unfamiliarity with best practice for work support $(91 \%)$; lack of perceived competency to assess work complexities ( $82 \%)$. Occupational therapy (OT) was identified as the most appropriate profession to address work (78\%). However, $51 \%$ respondents reported not routinely referring to OT for work support due to limited availability of OT (13\% of responders having no access to OT); uncertainty regarding optimum timing for work intervention, and uncertainty as to what OT could offer regarding work

Conclusions: Addressing work was recognised as multifaceted and multidisciplinary. Work needs are addressed within current rheumatology services only when the client themselves initiate the issue. Opportunity exists to improve the quality of services to address work in line with guidelines by educating the multidisciplinary team about available work services and implementation of a clinical pathway for employment retention.

Disclosure of Interest: None declared

DOI: 10.1136/annrheumdis-2017-eular.1107

\section{HPR patients' perspectives, functioning and health (descriptive: qualitative or quantitative)}

\section{AB1231-HPR LIVING WITH RHEUMATOID ARTHRITIS IN SPAIN. A QUALITATIVE STUDY}

A. Pedraz-Marcos ${ }^{1}$, C. Hale ${ }^{2}$, A. Palmar-Santos ${ }^{1}$, J. Zarco-Colon ${ }^{3}$, M. Ramasco-Gutierrez ${ }^{4}$, T. Velasco-Ripoll ${ }^{5}$, J. Martín-Alarcón ${ }^{6}$, N. Sapena-Fortea ${ }^{7}$ on behalf of Grupo de Investigación Cualitativa en Salud (GIQS-UAM). ${ }^{1}$ Surgery, University Autonoma of Madrid, Madrid, Spain:

${ }^{2}$ University of Leeds, Leeds, United Kingdom; ${ }^{3}$ Sociology, University Autonoma of Madrid; ${ }^{4}$ Public Health, Regional Health Organization; ${ }^{5}$ Rheumatology, Hospital la Princesa, Madrid; ${ }^{6}$ Hospital Clinic Barcelona, Barcelona, Spain; ${ }^{7}$ Rheumatology, Hospital Clinic Barcelona, Barcelona, Spain

Background: The impact of rheumatoid arthritis (RA) on the lives of people is a constant in the studies explored. However, research shows the lack of impact that this has on clinical consultations, despite the influence it may have on the attitude of the person with RA towards treatment adherence. In the Spanish context, except for the study by Devillard \& Otegui (1991), the experience of living with RA has scarcely been addressed.

Objectives: To explore the experience of living with RA in Spain.

Methods: In-depth interviews were conducted with a group of patients from two hospitals in the two main Spanish cities: Madrid and Barcelona. The interviews were conducted between April 2014 and February 2015. Thematic analysis was done, identifying the main themes and subthemes and organizing data in a coding framework that allows their interpretation

Results: Patients with disease activity moderate or severe (DAS28 >3.2), and already treated with DMARD, were aged 40-79, 15 were women and 4 men. Three main categories emerged from the discourses. (Table 1)

\begin{tabular}{|c|c|c|}
\hline \multirow[t]{2}{*}{$\begin{array}{l}\text { The symptoms and } \\
\text { their management }\end{array}$} & Go along with & $\begin{array}{l}\text { How do you live with this? Well, you } \\
\text { have to know how to bear it because it } \\
\text { is a life of always being tired. [..] You } \\
\text { wake upwith the body as ifyou had been } \\
\text { beaten. (EM7) } \\
\text { When they come [the children], I } \\
\text { pretend I'm not doing so badly. I make } \\
\text { myself up, I dress up, for they wouldn't } \\
\text { notice. (EB3) }\end{array}$ \\
\hline & Self-management & $\begin{array}{l}\text { You have to discover it by yourself, each } \\
\text { person what their own experience } \\
\text { teaches them. (EB7) }\end{array}$ \\
\hline \multirow[t]{3}{*}{ Daily life } & Home adapting & $\begin{array}{l}\text { I had a bath but now I have put a } \\
\text { shower. We have set up single lever } \\
\text { taps. I bought a step, because I cannot } \\
\text { stand on tiptoe to reach something. } \\
\text { (EBS) }\end{array}$ \\
\hline & Self image & $\begin{array}{l}\text { Of course, I have changed my shoes, I } \\
\text { used to wear heels before, and now I use } \\
\text { boots. (EB8) }\end{array}$ \\
\hline & Planning & $\begin{array}{l}\text { Always planning: you are not to } \\
\text { improvise under any circoonstances. } \\
\text { (EM9) }\end{array}$ \\
\hline \multirow[t]{2}{*}{$\begin{array}{l}\text { Therapeutic } \\
\text { strategies }\end{array}$} & The DMARD miracle & $\begin{array}{l}\text { When I take this medicine, I totally } \\
\text { revive. (EM7) }\end{array}$ \\
\hline & $\begin{array}{lr}\begin{array}{l}\text { Ambivalent } \\
\text { with }\end{array} & \text { relation } \\
\text { professionals } & \text { health }\end{array}$ & $\begin{array}{l}\text { I had an anful time ... The best thing is } \\
\text { people. For me, my rheronat ologist is } \\
\text { like God. (EB8) } \\
\text { T'm very frustrated.. when they have } \\
\text { been wrong with you a lot. (EM1) }\end{array}$ \\
\hline
\end{tabular}

Conclusions: RA patients know well what is it like to get up in the morning, tired, stiff, sore and having to rethink their day. Prioritization and planning activities are key to the organization of the activity and rest. Families and external aid, in case they can afford it, are the most common supports on which the requested supports pivot.

The constant development of new therapeutic strategies and outbreaks of the disease determine the use of an important therapeutic arsenal, with unpleasant side effects, and that should be administered in a hospital setting. This need to rely on medical treatment also extends to doctors, as part of the therapeutic strategy. Nurses are absent from the speeches of our participants

RA patients in our study feel they are mainly on their own to cope with their disease. The new therapeutic strategies have improved the symptoms' control, but they feel they need more than drugs to cope with their daily life. Contrary to the variety of professionals, institutions and organizations that try to empower patients to self manage their disease in other countries, the Spanish attention pivot mainly in rheumatologists.

\section{References:}

[1] Devillard, Marie Jose; Otegui, Rosario; García, Pilar. La voz callada. Aproximaciones antropológico-social al enfermo de artritis reumatoide. Madrid: Comunidad de Madrid. Consejería de Salud; 1991.

Disclosure of Interest: None declared

DOI: 10.1136/annrheumdis-2017-eular.3887

\section{AB1232-HPR THE EFFECT OF THE DRAINAGE ON PROPRIOCEPTIVE ACUITY INPATIENTS WITH TOTAL KNEE PROSTHESIS}

B. Ünver ${ }^{1}$, M. Eymir ${ }^{1}$, V. Karatosun ${ }^{2} .{ }^{1}$ School of Physical Therapy and Rehabilitation; ${ }^{2}$ Faculty of Medicine Surgery Medicine Department of Orthopaedics and Traumatology, Dokuz Eylül University, Izmir, Turkey, Izmir, Turkey

Background: With total knee replacement (TKR) surgery articular cartilage, meniscuses, articular ligaments are removed. Also articular effusion and 